\title{
ESPORTE, DESIGUALDADE, JUVENTUDE E PARTICIPAÇÃO
}

\author{
MS. QUÉFREN WELD CARDOZO NOGUEIRA \\ Mestre em Educação pela Universidade Federal de Uberlândia e Professor do \\ Departamento de Educação Física da Universidade Federal de \\ Sergipe (Sergipe - Brasil) \\ e-mail: quefrenweld@yahoo.com.br
}

\begin{abstract}
RESUMO
O presente texto apresenta reflexões sobre esporte e juventude tendo como referencia o conceito de participação no contexto da sociedade brasileira marcada pela desigualdade social. Para tanto, problematiza a constituição da desigualdade social no Brasil e como tal aspecto afeta diretamente os jovens. Enfim, debate sobre o lugar do esporte em políticas públicas para a juventude brasileira.
\end{abstract}

PALAVRAS-CHAVE: Esporte; juventude; desigualdade social; participação. 
Uma das características que podemos apontar sobre o Brasil refere-se ao reconhecimento da desigualdade social como um aspecto impregnado às estruturas da vida cotidiana. Para além da afirmação da nação como pobre, o que temos são as consequências da má apropriação e repartição das riquezas quando relacionadas com a capacidade produtiva do país.

Tanto a compreensão da desigualdade quanto a proposição de instrumentos para sua superação se situam nas complexas e contraditórias relações do Estado com os modos como a vida social é produzida mediante o trabalho, as relações sociais, os conhecimentos e as formas de comunicação entre grupos e pessoas. A desigualdade se situa, afirmam Behring e Boschetti (2008), na articulação de elementos históricos, econômicos, políticos e culturais, os quais, por sua vez, substanciam condições de possibilidade, forças de confronto e questões estruturais da economia com seus efeitos na produção e reprodução de vida social.

Apesar da desigualdade social marcar indiscriminadamente diversas parcelas da população, os grupos situados entre 15 e 29 anos são particularmente atingidos por processos de exclusão. Emprego precoce e subemprego, escolarização precária, exílio em bairros decadentes, etc. possuem características particulares quando a discussão é focada na juventude: a desigualdade social tem provocado uma concepção do jovem como um problema social, propenso à delinquência e ao uso de drogas, devendo, portanto, tomar parte de projetos de sociais capazes de promover uma 'correta' socialização.

No contexto das políticas públicas para a juventude, encontramos o trabalho com o esporte como uma das principais estratégias de intervenção. Principalmente pelo uso de argumentos educativos, existe a crença de que as atividades podem minimizar os efeitos negativos das crianças estarem nas ruas (VIANA; LOVISOLO, 2009). O esporte é visto como um antídoto para a ocupação do tempo livre, numa concepção que indica uma suposta linearidade entre a falta de lazer e o mundo do crime (MELO, 2005). Por outro lado, como instrumento de disciplina para evitar o envolvimento com as drogas e com a violência, ao invés de questionar as próprias bases que sustentam a desigualdade social, o esporte valida ações capazes de exercer, interpretando Abad (2007) noutro contexto, a força mediante a coerção, coação ou repressão.

Em contrapartida, torna-se imperioso discutir intervenções tendo o jovem como protagonista das ações, parceiros na elaboração, implementação, desenvolvimento e avaliação das propostas. "Trata-se de compor novos desenhos que constituam de fato os jovens como sujeitos capazes de expressar as ações, e participar dessas ações, 
que, antes de tudo, dizem respeito a eles mesmos" (SPOSITO, 2008, p. 73). Pela necessidade de rever os processos de produção e reprodução da vida social, e com o intuito de romper com a 'lógica reiterativa das desigualdades', busca-se criar oportunidades de reconstrução pessoal, de experiências positivas de participação e reconhecimento (ASSEBURG; GAIGER, 2007); ou ainda, "[...] garantir objetividade nas propostas políticas dos jovens, como forma de sedimentar a participação juvenil como sujeito na elaboraçã̃o de propostas das respectivas ações do poder público (NEVES; FERRERI, 2008, p. 130)".

Dados apresentados pelo IBASE (Instituto Brasileiro de Análises Sociais) e pelo POLIS - Instituto de Estudos e Formação e Assessoria em Políticas Públicas, numa pesquisa intitulada 'Juventude Brasileira e Democracia', mostram alguns aspectos apontados pelos próprios jovens: ( I ) os jovens demonstram não encontrar espaços de negociação e resolução de suas questões, ou canais de expressão de opiniões para a melhoria de vida; (2) denunciam as condições da escola pública evidenciando a falta de infra-estrutura, baixos salários dos professores, aulas pouco atraentes, violência em torno da escola e constante falta de professores; (3) falta de trabalho como agravante do aspecto econômico, cultural e societário; (4) alto custo das atividades artístico-culturais, falta de segurança nos espaços de lazer e a centralização de oportunidades nas áreas nobres dos grandes centros urbanos.

De posse de tais elementos, o objetivo desse texto é debater sobre o esporte como ferramenta na constituição de políticas sociais para e com a juventude, o que exige abordar discussões sobre a desigualdade social e suas relações com os conceitos de cultura e participação. Para tanto, serão destacados aspectos sobre as condições estruturais da desigualdade e o modo como tal elemento atinge particularmente a juventude brasileira. "Enfim, serão apontados questionamentos para as políticas públicas que possuem nas práticas esportivas uma estratégia de intervenção.

\section{ALGUMAS CONDIÇÕES ESTRUTURAIS DA DESIGUALDADE}

Os apontamentos sobre a relação entre esporte e juventude trazem à tona o conceito de participação e suas relações com a questão da desigualdade social. $\mathrm{Na}$ democracia liberal, explica Chauí (2007), tanto a igualdade como a desigualdade são condições naturais do ser humano: enquanto o direito de propriedade do corpo nos faz iguais, nascemos com talentos e capacidades desiguais. Pela tendência da sociedade de fortalecer a desigualdade, é necessário produzir uma segunda igualdade proporcionada pela lei, ou seja, "[...] a desigualdade é um fenômeno natural produzido pela sociedade, enquanto a desigualdade é e sempre será um dado, a igualdade é uma conquista histórica" (CHAUÍ, 2007, p. 21 I). 
Para compreender a desigualdade a partir de uma dimensão social, política e econômica faz-se necessário apontar com Sales ( 1994), como no Brasil a herança colonial implica o favor, a dádiva, o mando e a subserviência como aspectos estruturais de nossa condição política. Como consequência, temos a construção de uma 'cidadania concedida', em que os direitos civis - de ir e vir, de justiça, direito à propriedade, direito ao trabalho - são outorgados aos homens livres mediante concessão de outrem. Mesmo com a implantação da República, a cidadania continua algo a ser concedido, particularmente pela troca de favores: de um lado, estão os chefes municipais e os coronéis e, de outro, os que possuem os erários, os empregos, os favores e a força policial - situação que se perpetua até os dias atuais.

A construção da igualdade é condicionada pela formação de uma massa submissa tanto política como economicamente, tornando foco das políticas públicas a redução dos conflitos sociais (BEHRING; BOSCHETTI, 2008). Tais características condizem com o modo como a sociedade coloca em prática, dizem Asseburg; e Gaiger (2007, p. 50 I), uma "dinâmica permanente de produção-mudançareprodução das desigualdades".

Como categoria central para compreender a atual conjuntura social, o fenômeno da globalização representa a forma mais atualizada da expansão dos mercados e da oferta de mercadorias. Desse ponto de partida, é preciso reconhecer a independência da mercadoria do seu processo de produção, do ocultamento das relações sociais, ou como colocam Belloni; Magalhães; Sousa (2007), omitir a complexidade existente entre o sistema educativo e o produtivo - trata-se, com Lukács (2003), do 'fetichismo da mercadoria' como característica central do capitalismo moderno. A mercadoria concretizada pelo consumismo é capaz de produzir, remodelar necessidades e transformar os próprios consumidores em produtos, tratando-se também do que Bauman (2008) denomina de 'fetichismo da subjetividade'. Nesse contexto, afirma Giraud (2007), mesmo com a vangloriada inevitabilidade da globalização, o que temos efetivamente é um processo que atualiza contradições.

Além disso, o poder da informação, expresso particularmente pela cibernética (informática e eletrônica), capaz de revolucionar a maneira como significados são produzidos e identidades formadas, representa o aumento da riqueza de grandes corporações multinacionais, a homogeneização dos cenários sociais, a privatização e o abandono à lógica do mercado de serviços básicos como educação, saúde e habitação (GIROUX, 2003). Temos a nível mundial, conforme Santos (200 I), empresas intercontinentais que competem entre si, demandando e valendo-se de avanços tecnológicos e científicos para se sobreporem umas às outras. Tomam forma nessa perspectiva duas manifestações tirânicas: a tirania do dinheiro e a tirania da informação, ambas legitimadas pelo pensamento único, pela adaptação passiva e 
homogeneização do conhecimento. Constrói-se um corolário de perversidades em que, enquanto o consumo torna-se o denominador comum em todos os indivíduos, a competição se apresenta como regra fundamental de convivência.

É possível falar de processos engendrados pela desigualdade, como por exemplo, a exclusão social, cujas características referem-se, aponta Lopes (2008) apud Antunes (1 995), Paugam (1 999), Castell (1999), Bauman (2005), Honneth (1992) e Xiberras (1993) e Sung (2002), respectivamente: à precarização do trabalho, desqualificação social, desfiliação social, desagregação identitária, desumanização do outro e anulação da alteridade. Tais processos fazem emergir e difundem como manifestações típicas da realidade, o desemprego estrutural, a fome, a violência, a população de rua, falta de acesso a bens básicos, insegurança.

Para Chauí (2007), chegamos ao entendimento de uma sociedade que, ao proclamar a igualdade, está de fato dissimulando a desigualdade. Nesse contexto, as políticas denominadas sociais só podem se caracterizar como paliativas, pois as questões estruturais de sustentação das desigualdades não são questionadas; ou ainda, "[...] a política social não determinada a economia, mas é determinada por ela" (CHAUÍ, 2007, p. 226).

\section{DESIGUALDADE, JUVENTUDE E PARTICIPAÇÃO}

A par de uma discussão sobre a desigualdade social, caminhamos para uma análise de condições particulares da juventude. É possível afirmar que no capitalismo central e periférico, a pobreza e a exclusão social 'jovializaram-se' (FRIGOTTO, 2004, p. 197). Segundo dados do IBGE (Instituto Brasileiro de Geografia e Estatística), colocados por Castro e Aquino (2008), em 2006, o Brasil possuía uma população de 5I,I milhões de pessoas com idade entre 15 e 29 anos, correspondendo a 27,4\% da população. Nesses, a trajetória escolar é irregular e com marcas de fracasso - a frequência ao Ensino Médio em idade adequada não abrange metade dos jovens entre 15 e 17 anos, sendo que 61,6\% já abandonaram a escola pelo menos uma vez.

Como agravante, temos a situação do trabalho no Brasil, onde 42,2\% dos homens jovens deixam a escola para trabalhar em locais com baixas condições e são mal remunerados. Encontramos ainda a questão da violência e criminalidade, sendo que no período de 2003-2005, as mortes de jovens por homicídio atingiram uma média anual de 28.273. No caso da criminalidade, a participação de jovens em crimes relatados à polícia, a população entre 18 e 24 anos foi de 17,56 ocorrências por 100 mil habitantes; 387,74 por lesões corporais; 2 I 8,23 por roubo a transeuntes; 20,24 por roubo de veículos; 14,57 por estupro; 41,96 por posse de drogas. 
É possível analisar também o modo como a vida cotidiana é marcada por elementos socioeconômicos e padrões de discriminação e preconceito. Tais elementos se concretizam de forma bastante diversificada: quanto à renda, 31,3\% são considerados pobres (renda familiar per capita de 1/2 salário mínimo); 8,6\% com renda superior a 2 salários mínimos; $60 \%$ está no intermediário entre 1/2 e 3 salários mínimos. De acordo com regiões do país, o Nordeste possui 50,8\% dos jovens de baixa renda. Questões de raça e gênero também são marcas registradas da desigualdade social: no caso da educação, o número de analfabetos negros é quase três vezes maior do que de jovens brancos; a taxa de frequência no ensino médio é de $58,6 \%$ dos brancos contra $37,6 \%$ dos jovens negros. Já no caso da desigualdade envolvendo questões de gênero, os dados mostram que $27,1 \%$ dos jovens de 15 a 17 anos conciliam estudo e trabalho e I I,3\% só trabalham; essa proporção para as jovens é de 17,5 e 4,9\% respectivamente. Enfim,

O lado perverso disso é que o olhar da sociedade sobre os jovens dos setores populares quase que se restringe ao registro da criminalidade. Nesse sentido, o debate sobre a juventude e violência não pode se furtar a analisar, entre outros, a questão do recrutamento de jovens para atividades criminosas e as facilidades ainda vigentes para obter uma arma de fogo no país, bem como o processo de educação e formação dos jovens em meio a um contexto de banalização da violência ou mesmo a uma dinâmica férrea da reprodução das desigualdades e da exclusão social (CASTRO; AQUINO, 2008, p. 24).

Com isso, a juventude tornou-se um problema social e categoria central em políticas públicas (ABAD, 2008). Em muitas ações, discutem Castro; Aquino (2008), os jovens são associados à delinquência, comportamento de risco e uso de drogas, necessitando de ações focadas na preparação para uma vida adulta socialmente ajustada e produtiva. Preocupante nesse contexto, é a trilha que nos conduz, afirmam Neves e Ferreri (2009), para uma inviabilização permanente de um projeto de sociedade justa, democrática e solidária, que possui como princípio básico o respeito ao outro.

Por outro lado, constata Abramo ( 1997$)$, existem projetos que procuram reformular o modo como as ações são fomentadas. Partindo da ideia de protagonismo, os jovens são concebidos como capazes de formular questões significativas, propor ações relevantes, sustentar uma relação dialógica com outros atores e contribuir para a solução de problemas. Com isso, nos lembra Pontual (2008, p. I I 4), buscase incorporar os atores diretamente interessados nas ações desenvolvidas, mesmo sabendo que "é muito fácil falar em participação, em discussão, mas o grande desafio é criar espaços específicos, deliberativos para as pessoas que estão envolvidas na construção dessas esferas públicas". 
Torna-se imperioso redefinir o conceito de participação de modo a reconfigurar as intervenções realizadas. Em uma sociedade marcada pelo consumo fugaz e descartável, a participação, explica Chauí (2007), é algo passivo, imposto como uma estrutura formal, que deve servir a um planejamento pré-existente. Por outro lado, agora com Gohn (2008), falar em participação presume um processo de vivência com sentido e significado para aqueles que participam das ações. É necessário que o indivíduo esteja inserido em práticas de significação condizentes com a criação de processos identitários individuais e coletivos, abrindo espaços para a efetiva conquista da autonomia, a qual, nas palavras de Chauí (2007), representa uma posição dos sujeitos em ações efetuadas por eles próprios, enquanto criadores das regras e das formas de ação. Assim, a autonomia está relacionada com a capacidade dos indivíduos de, em dadas condições, interpretar, conhecer, determinar os requisitos e transformar os objetos sociais. Nesse sentido, novamente com Gohn (2008), a autonomia se refere ao modo como o sujeito histórico ler e interpreta o mudo, lidando com as diferenças e as singularidades, aprende a dialogar e busca o diálogo que leva ao entendimento. A diferença aqui é tomada como uma construção histórica e cultural, no sentido apontado por Giroux (1999), em que se reconhecem os legados históricos da colonização e como significados e representações sociais particulares são produzidas para legitimar relações de poder específicas.

Tais pressupostos nos conduzem para uma discussão sobre as relações entre cultura e participação, no sentido de que as práticas culturais nos informam sobre contextos sociopolíticos onde o conceito de participação pode tomar determinadas formas.

\section{CULTURA E PARTICIPAÇÃO}

A redefinição do conceito de participação no trabalho com a juventude toma como referência o campo da cultura ou o modo como a cultura tornou-se uma ferramenta essencial para fomentar modos de participação política e social. Para Yúdice (2004), há atualmente uma expansão da cultura para as esferas política e econômica, com um discurso que evoca uma 'cidadania cultural' como forma de organização social tendo em vista a emancipação. A cultura é tomada, na esteira de Giroux (2003), como uma dimensão política envolvida com o poder tanto para regular imagens e significados quanto para identificar noções de sujeito por meio de formas de conhecimento, valores, ideologias e práticas sociais. Há a exigência de tomar a cultura, coloca Bhabha (1998), não como produção regular ou canônica, mas composta por demandas incomensuráveis, produzidas 'no ato da sobrevivência social', muitas vezes marcadas pela experiência afetiva da marginalidade. Como consequência, Bentes e Herschmann (2002, p. 10), ao discutirem, por exemplo, o Hip-Hop, o Funk e o Rap pressupõem 
Analisar esses fenômenos culturais neste momento significa, por exemplo, tratar a música cantada por esses jovens dentro de um novo contexto, mais amplo, em que as 'culturas das favelas' aparecem não simplesmente como subprodutos da violência social do país, mas como uma produção e um discurso capazes não só de espelhar a realidade dura dessas realidades, mas que também, de alguma forma, exprimem a reivindicação da ampliação da cidadania ao segmento social que habita essas áreas urbanas.

A construção de uma cidadania cultural parte do entendimento do jovem como capaz de ação e intervenção social, dando crédito para, colocam Neves; Ferreri (2008), ações educativas lúdicas contrárias a outras que se baseiam na intimidação ou punição. Para isso, agora com Giroux (1999), é necessário entender a aprendizagem como uma forma de envolvimento o qual mobiliza e reconstrói desejos, como um processo em que o corpo se movimenta, aprende, deseja e anseia por afirmação e reconhecimento.

A dimensão cultural orienta um modo de compreender e reivindicar uma dimensão da cidadania como contraponto ao que Neves (2007) denomina de 'déficit simbólico'; ou seja, a limitação do exercício da cidadania não se dá somente em termos legais (civis, políticos e sociais), mas também pela ausência da noção de pertencimento, e de uma cidadania simbólica que fazem dos sujeitos reconhecerem a si mesmos como plenos de direitos. Em consequência desta reivindicação, o "[...] reconhecimento dos direitos e da identidade de grupos minoritários marcados por estigmas e desprezo social é fundamental para a consolidação da democracia e a ampliação da igualdade entre nós" (NEVES, 2007, p. I | 8).

É nesse sentido que podemos dialogar com Asseburg e Gaiger (2007) para compreender como o combate à desigualdade necessita de ações efetivas para impulsionar o protagonismo como um dos requisitos contrários à perpetuação da exclusão social. Considerando que as pessoas são constantemente minimizadas da condição de agentes, é necessário oferecer oportunidades de reconstrução da experiência pessoal, com práticas positivas de participação e reconhecimento que enfatizem a construção de espaços para a recuperação da dignidade, num posicionamento contrário à privação de capacidades e focadas em ações participativas de cooperação e de autogestão.

Com essa perspectiva, algumas recomendações foram feitas pelo IBASE e POLIS para implementar políticas para a juventude: (a) constituir espaços públicos, centros e clubes culturais, artísticos e esportivos, democraticamente gerenciados para potencializar a participação e associativismo dos(as) jovens e estimular a constituição de hábitos culturais participativos e democráticos; (b) investir em ações que favoreçam a melhoria da qualidade de ensino; (c) dar condições para iniciativas na área do esporte, da cultura e da capacitação profissional, consideradas essenciais 
para o aumento da atratividade e do interesse dos(as) alunos(as) pela escola; (d) elaborar programas de apoio a iniciativas culturais, científicas e esportivas.

\section{E O ESPORTE?}

Pode-se afirmar que atualmente o esporte se tornou uma das principais ferramentas de intervenção em políticas públicas para a juventude. As justificativas para as propostas são distintas, mas se orientam, apontam Vianna;Lovisolo (2009), principalmente pelos aspectos de ordem moral ou de personalidade dos seus praticantes. Ainda, com a promulgação tanto da Constituição Federal de 1988, quanto Estatuto da Criança e do Adolescente (ECA), explicam Oliva e Kauchakje (2009), as crianças e os adolescente foram considerados como prioridade na rede proteção de social do Estado, tendo o esporte um lugar privilegiado em propostas de intervenção.

Comumente, o esporte é tido como um antídoto para a ocupação do tempo livre, numa concepção que indica, afirma Melo (2005), uma suposta lineariedade entre a falta de lazer e o mundo do crime. Ganha força em políticas públicas, parcerias público-privadas e organizações não governamentais um trabalho que busca retirar as crianças da rua, combater a criminalidade e a violência. As propostas comumente identificam uma sociedade que paulatinamente perde seus valores e uma juventude incapaz de ativismo e participação política.

\footnotetext{
Nota-se a emergência da vinculação entre as políticas esportivas e o discurso da promoção da cidadania ou de inclusão social. Ou então uma outra tendência ainda é a de considerar o esporte importante mecanismo de controle social da juventude, visando apenas dominar os impulsos violentos e produzir uma nova sociabilidade, capaz de gerar novas práticas que possam afastar os jovens de drogas e crimes, numa abordagem salvacionista (MELO, 2005, p. 80).
}

Tal perspectiva cresce juntamente com a relação entre Estado e a promoção de grandes eventos esportivos. A participação financeira do Governo Federal na organização dos Jogos Pan-Americanos Rio 2007, a realização da Copa do Mundo da FIFA Brasil 2014 e dos Jogos Olímpicos em 2016 mostram o interesse do Estado em apresentar seu poder de organização e investimento do dinheiro público em ações esportivas. Todavia, em grandes eventos é reforçado, assim como analisa Linhales ( 1997), o desenvolvimento das capacidades esportivas de uma nação como intrinsecamente ligado às orientações e interesses do mercado, particularmente quando da presença de uma indústria esportiva e midiática como fonte para a produção do esporte espetáculo e para a comercialização de uma infinidade de produtos e serviços ligados à prática esportiva. Assim, temos, apontam Bracht e Almeida (2003, p. 91) 
a "[...] passagem de um modelo de esporte que o entendia como um bem social, como um direito deste, para a ideia do esporte como um direito do consumidor". Nessa perspectiva, discute Mascarenhas (2006), o lazer vai aos poucos adquirindo a forma de mercadoria e, portanto, assume o caráter de coisa, determinado pelas necessidades econômicas, políticas, sociais e culturais do capitalismo.

Por outro lado, se para Vago (1999), o desafio atual está em tratar pedagogicamente o esporte como uma prática efetivamente educativa, que estabelece relações tanto pacíficas como conflituosas com outras esferas sociais, para Taffarel (2009), diversas são as tentativas de fundamentar a prática pedagógica da Educação Física para além da adaptação progressiva do corpo ao esforço, indo ao encontro de uma intervenção capaz de trabalhar o esporte de forma crítica, reflexiva e inserida nos projetos pedagógicos das instituições escolares.

Nesse contexto, é necessário construir propostas pedagógicas capazes tanto de problematizar o lugar social do esporte, como de fortalecer seu papel como vetor para a construção de uma sociedade justa e igualitária. Toma força a necessidade de tratar pedagogicamente o esporte para que esse atenda aos objetivos educacionais vinculados com princípios democráticos e cidadãos. No trabalho com o esporte, é preciso mobilizar um conjunto de conhecimentos que promovam práticas pedagógicas orientadas pelos princípios éticos da autonomia, responsabilidade, solidariedade e do respeito ao bem comum; princípios políticos dos direitos e deveres de cidadania, do exercício da criticidade e do respeito à ordem democrática; dos princípios estéticos da sensibilidade, criatividade, ludicidade e da diversidade de manifestações artísticas e culturais'. Não se trata, portanto, de uma discussão centrada na busca incessante pelo rendimento ininterrupto, mas sim da possibilidade da prática educativa se tornar um vetor político e cultural de experiências positivas focadas na participação, no reconhecimento de potencialidades, no desenvolvimento de capacidades, na afirmação das diferenças e no fortalecimento de identidades.

Principalmente após o trabalho de Soares et al (1992), toma força um discurso em que a promoção da cidadania e justiça social ocorrem pelo reconhecimento do esporte como manifestação cultural, o que nos permite utilizar, com Yúdice (200 I), a noção da cultura a serviço da justiça social e, numa conotação para esse trabalho, o esporte a serviço da justiça social, com características, apontam Neves e Ferreri (2008), de transformação das atuais conjunturas geopolítica e socioeconômica, que tomem o jovem como sujeito político fundamental na tomada de decisões e implemento das ações.

I. RESOLUÇÃO CEB Nº 2, de 7 de abril de 1998 que institui as Diretrizes Curriculares Nacionais para o Ensino Fundamental. 
Intervenções com tais características reconhecem o esporte como instrumento de crítica e ferramenta de participação efetiva quando colocam que (I) as políticas públicas para o desenvolvimento humano são também políticas de esporte. Como forma de combater processos históricos de marginalização e exclusão, a criação de possibilidades para a prática esportiva deve permitir o acesso de todos, independente da raça, classe, gênero, idade, necessidade especial; (2) o esporte como um bem cultural pode ser trabalhado na perspectiva do desenvolvimento humano, pela promoção de experiências focadas na participação, no processo, na formaçãa de grupos heterogêneos, na cooperação, na convivência com o distinto e com o diverso; (3) o esporte é fruto de projetos e intencionalidades, o trabalho proposto e realizado pode se pautar na solidariedade, respeito ao próximo, valorização da pluralidade cultural e da vida saudável; (4) o esporte é uma ferramenta tornada indispensável para a construção de oportunidades em que as pessoas são convidadas a participarem na condição de agentes; (5) o esporte pode ser praticado em diversos espaços, particularmente os públicos, o que exige uma qualificação desses espaços e dos profissionais que neles atuam; (6) a prática esportiva exige a capacitação de técnicos e professores, o incentivo à pesquisa, intercâmbios e cursos, clareza na gestão de recursos públicos, etc, abrindo espaços para a qualificação profissional e geração de emprego e renda.

Nesse sentido, alguns questionamentos são balizadores tanto para políticas públicas como para futuras pesquisas empíricas: (I) as ações assumem um caráter coletivo, envolvendo os jovens no processo de gestão da prática esportiva?; (2) assumem um caráter coletivo porque promovem o diálogo entre o esporte escolar e diversas outras instituições e dimensões do esporte e da comunidade?; (3) tendem a criar vínculos de mediação e representação com o intuito de promover a expansão da prática esportiva na escola e fora dela?; (4) possuem como foco a construção de experiências positivas em situações esportivas? (5) abrem espaços para a discussão coletiva e apresentação de propostas?; (6) abrem espaços para o trabalho com outras práticas corporais como a dança, a luta, a ginástica, a brincadeira, etc.?; (7) possibilitam o trato pedagógico com o esporte tomando por base diversos artefatos culturais como a música, o cinema, o teatro, a televisão, a poesia, dente outros?

As discussões sobre o papel do esporte em políticas públicas para a juventude invocam uma concepção de cultura e participação como aspectos indispensáveis para enfrentar o problema da desigualdade social. Nesse sentido, não é mais possível perceber o jovem como receptor de políticas públicas, mas como agente capaz de mobilização e intervenção social. Tal concepção está ancorada em perspectivas mais amplas, que procuram redefinir o próprio conceito de democracia pelo viés da participação social, ou pela construção de uma democracia participativa. No caso 
do esporte, autores como Neri e Suassuna (2009) e Terra "et al " (2009) vêm apontando como esse marco no Brasil está tomando forma, por exemplo, na realização das Conferências Nacionais de Esporte, cuja organização busca envolver, ainda que de forma limitada, a população nas decisões governamentais.

De qualquer forma, os aspectos contraditórios e complexos que caracterizam o esporte tendem para intervenções que ora reforçam, ora enfraquecem conceitos como participação, cidadania, justiça social e democracia. Somente o esporte não é capaz de resolver o problema da desigualdade social, mas é fato que se não o utilizarmos em função da melhoria da qualidade de vida das pessoas e para a transformação dos modos de produção e reprodução da vida social, perderemos a oportunidade histórica de construir uma sociedade justa e igualitária.

\section{Sport, youth, inequality and participation}

ABSTRACT: The following text reflects about youth and Sport having as a central point the concept of participation in the context of inequality of Brazilian society. Whatsoever argues about the constitution of inequality in Brazil e how this aspect directly affects the young people. At last, debates about the place of sport in public politics for Brazilian youth.

KEY-WORDS: Sport, youth, social inequality, participation.

\section{Deporte, juventud, desigualdad y participación}

RESUMEN: El presente texto presenta reflexiones sobre deporte y juventud teniendo como referencia el concepto de participación en el contexto de la sociedad brasileña marcada por la desigualdad social. Por lo tanto, problematiza la constitución de la desigualdad social en Brasil y como tal aspecto afecta directamente a los jóvenes. Finalizando, cuestiona sobre el lugar del deporte en políticas públicas para la juventud.

PALABRAS-CLAVE: Deporte, juventud, desigualdad social, participación.

\section{REFERÊNCIAS}

ABAD, M. Crítica política das políticas públicas. IN: FREITAS, M. V. de.; PAPA, F. de C. (org.). Políticas públicas: juventude em pauta. 2. ed. São Paulo: Cortez: Ação Educativa Assessoria, Pesquisa e Informação: Fundação Friedrich Elbert, 2008, p. 13-32.

ABRAMO, H. W. Considerações sobre a tematização da juventude no Brasil. Revista Brasileira de Educação, Rio de Janeiro, n. 5/6, p. 25-36, maio/dezembro de 1997.

ASSEBURG, H. B.; GAIGER, L. I. A economia solidária diante das desigualdades. Dados Revista de Ciências Sociais. Rio de Janeiro, v. 50, n. 03, p. 499-533, 2007. 
BENTES, I. M.; HERSCHMANN, M. O espetáculo do contra-discurso. Folha de São Paulo, São Paulo, p. 10-1।, 18 ago. 2002.

BAUMAN, Z. Vida para consumo: a transformação das pessoas em mercadorias. Rio de Janeiro: Jorge Zahar Ed., 2008.

BEHRING, E. R.; BOSCHETTI, I. Política social: fundamentos e história. São Paulo: Cortez, 2008.

BELLONI, I.; MAGALHÃES, H. de.; SOUSA, L. C. de. Metodologia de avaliação em políticas públicas. São Paulo: Cortez, 2007.

BHABHA, H. K. O local da cultura. Belo Horizonte: Ed. UFMG, 1998.

BRACHT, V.; ALMEIDA, F. Q. de. A política de esporte escolar: a pseudovalorização da educação física. Revista Brasileira de Ciências do Esporte, Campinas, v.24, n. 03, p. 87-102, maio 2003.

CASTRO, J. A.; AQUINO, L. (org.). Juventude e políticas sociais no Brasil. Brasília: IPEA, 2005. Disponível em: <http://www.ipea.gov.br/sites/000/2/publicacoes/tds/td_1335.pdf. Acesso em: 12 outubro 2009.>

CHAUÍ, M. Cultura e democracia: o discurso competente e outras falas. São Paulo: Cortez, 2007.

FRIGOTTO, G. Juventude, trabalho e educação no Brasil: perplexidades, desafios e perspectivas. IN: NOVAES, R.; VANNUCHI, P. (org.). Juventude e sociedade: trabalho, educação, cultura e participação. São Paulo: Editora Fundação Perseu Abramo, 2004, p. 180-216.

GIRAUD, O. A globalização vista de norte a sul: quais seus mecanismos sociais?. Cadernos CRH, Salvador, n. 20, n. 5I, p. 389-399, setembro/dezembro 2007.

GIROUX, H. Cruzando as fronteiras do discurso educacional: novas políticas em educação. Porto Alegre: Artes Médicas Sul, 1999.

Atos impuros: a prática política dos estudos culturais. Porto Alegre: Artmed, 2003.

GOHN, M. da G. O protagonismo da sociedade civil: movimentos sociais, ONGs e rede solidárias. São Paulo: Cortez, 2008.

IBASE; POLIS. Diálogo para uma política pública de juventude. Rio de Janeiro: IBASE, São Paulo, Pólis, 2006. Disponível em: <http://www.aracati.org.br/portal/pdfs// 3 _Biblioteca/ Estudos\%20e\%20pesquisas/livreto\%20pesquisa\%20lbase.Polis.pdf.> Acesso em: I2 outubro 2009.

LINHALES, M. A. Políticas públicas para o esporte no Brasil: interesses e necessidades. IN: SOUSA, E. S.; VAGO, T. M. (org.). Trilhas e partilhas: Educação Física na cultura escola e nas práticas sociais. Belo Horizonte: Gráfica e Editora Cultura, 1997, p. 219-230. 
LOPES, J. R. Processo sociais de exclusão e políticas sociais de enfrentamento da pobreza. Caderno CRH, Salvador, v. 2 I , n. 53, p. 349-363, maio/agosto 2008.

LUKÁCS, G. História e consciência de classe: estudos sobre a dialética marxista. São Paulo, 2003.

MASCARENHAS, F. Em busca do ócio perdido: idealismo, panacéia e predição histórico à sombra do lazer. IN: PADILHA, V. (org.). Dialética do lazer. São Paulo: Cortez, 2006, p. $75-103$.

MELO, M. Paula de. Esporte e juventude pobre: políticas públicas de lazer na Vila Olímpica Maré. Campinas: Autores Associados, 2005.

NERI, A. A.; SUASSUNA, D. Notas acerca da democracia participativa e as políticas de esporte e lazer. In: CONGRESSO BRASILEIRO DE CIÊNCIAS DO ESPORTE, 2009, Salvador, Anais ... Disponível em <http://www.rbceonline.org.br/congressos/index.php/ CONBRACE/XVI/paper/view/I074/805. Acesso em: I I maio 20 I0.>

NEVES, P. S. C.; FERRERI, M. Políticas públicas de juventude: nova arquitetura para o debate sobre educação. IN: CRUZ, M. H. S. (org.). Pluralidade de saberes e territórios de pesquisa em educação sob múltiplos olhares dos sujeitos investigadores. São Cristovão: Editora UFS, 2009. p. | $25-148$.

NEVES, P. S. C. Reconhecimento e desprezo social ou dilemas da democracia no Brasil contemporâneo: algumas considerações à luz da questão social. Politica \& sociedade, v. 6, p. | |7-।32, 2007.

OLIVA, J. C. G. O.; KAUCHAKJE, S. As políticas sociais públicas e os novos sujeitos de direito: crianças e adolescentes. Rev. Katál. Florianópolis, v. 12, n. 01, p. 23-31, janeiro/ junho 2009.

PONTUAL, P. Juventude, exclusão e inclusão social: aspectos e controvérsias de um debate em curso. In: FREITAS, M. V. de.; PAPA, F. de C. (org.). Políticas públicas: juventude em pauta. São Paulo: Cortez, 2008. p. 95- | 14.

SALES, T. Raízes da desigualdade social na cultura política brasileira. Revista Brasileira de Ciências Sociais, São Paulo, v. 25, n. 09, p. 26-37, 1994.

SANTOS, M. Por uma outra globalização: do pensamento único à consciência universal. $7^{\text {a }}$ edição. Rio de Janeiro: Record, 2001 .

SOARES et al. Metodologia do ensino da educação física. São Paulo; Cortez, 1992.

SPOSITO, M. Trajetórias na constituição de políticas de juventude no Brasil. IN: FREITAS, M. V. de.; PAPA, F. de C. (org.). Políticas públicas: juventude em pauta. São Paulo: Cortez: 2008. p. 57-94.

TAFFAREL, C. Z. N. Desporto educacional: realidade e possibilidades das escolas políticas públicas governamentais e das práticas pedagógicas nas escolas públicas. In: STIGGER, M.P.; 
LOVISOLO, H. (orgs.). Esporte de rendimento e esporte na escola. Campinas: Autores Associados, 2009, p. 71-102.

TERRA, A. M., et al. As conferencias nacionais de esporte: avanços e limites na construção de políticas públicas de esporte e lazer.CONGRESSO BRASILEIRO DE CIOÊNCIAS DO ESPORTE, Salvador, Anais ... Disponível em: <http://www.rbceonline.org.br/congressos/ index.php/CONBRACE/XVI/paper/view/775/806. > Acesso em: I I maio 2010.

VAGO, T. M. Intervenção e conhecimento na escola: por uma cultura escolar de Educação Física. IN: GOELLNER, S. (org.). Educação Física/Ciências do Esporte: intervenções e conhecimento. Florianópolis: Colégio Brasileiro de Ciências do Esporte, 1999, p. 17-36.

VIANA, J. A.; LOVISOLO, H. R. Projetos de inclusão social através do esporte: notas sobre a avaliação. Revista Movimento, Porto Alegre, v. I5, n. 03, p. |45- |62, abril/junho de 2009.

YÚDICE, G. A conveniência da cultura: usos da cultura na era global. Belo Horizonte: Editora UFMG, 2004.

Recebido: 22 out. 2009

Aprovado: 18 mai. 2010

Endereço para correspondência: Quéfren Weld Cardozo Nogueira Alameda Gilberto Vieira Leite, 99

Bairro Coroa do Meio

Aracaju - Sergipe

CEP: 49035-360 